\title{
ANALISA FAKTOR-FAKTOR YANG MEMPENGARUHI KINERJA KARYAWAN PADA CUSTOMER EXPERIENCE DEPARTMENT
}

\author{
Rycko Andhika \\ Program Studi Magister Manajemen Universitas Tarumanagara \\ ryckoandhika@gmail.com
}

Masuk : 09-06-2019, revisi : 22-08-2019 diterima untuk diterbitkan : 23-08-2019

\begin{abstract}
The purpose of this study is to find out 1) whether there is an effect of leadership style on employee performance 2) whether there is an effect of motivation on employee perfromance 3) whether there is a employee engagement on employee performance The population in this study were customer experience department. The sample used in this study was 108 respondents. The sampling technique used was nonprobability sample. Overall the results of this study are 1) Leadership style has a significant effect on employee performance, 2) Motivation has a significant effect on employee performance, 3) Employee engagement has a significant effect employee performance.
\end{abstract}

Keywords : Leadership Style, Motivation, Employee Engagement, Employee Performance

Abstrak : Tujuan penelitian ini adalah untuk mengetahui 1) apakah terdapat pengaruh gaya kepemimpinan terhadap kinerja karyawan 2) apakah terdapat pengaruh motivasi terhadap kinerja karyawan 3) apakah terdapat pengaruh employee engagement terhadap kinerja karyawan. Populasi dalam penelitian ini adalah customer experience department. Sampel yang digunakan pada penelitian ini yaitu 108 responden. Teknik pengambilan sampel yang digunakan yaitu nonprobability sample dengan metode Secara keseluruhan hasil dari penelitian ini yaitu 1) Kualitas gaya kepemimpinan berpengaruh signifikan terhadap kinerja karyawan, 2) motivasi berpengaruh signifikan terhadap kinerja karyawan, 3) employee engagement berpengaruh signifikan terhadap kinerja karyawan.

Kata kunci : Gaya Kepemimpinan, Motivasi, Employee Engagement, Kinerja Karyawan

\section{Pendahuluan}

Bisnis start up yang bergerak dalam bidang teknologi transportasi saat ini sedang berkembang di Indonesia, dengan munculnya transportasi online yang mulai marak sejak awal tahun 2015. Transportasi yang ada saat ini memberikan pengaruh besar terhadap masyarakat terhadap kemudahan dalam melakukan mobilisasi dan memberikan layanan yang memuaskan, harga yang sesuai, rasa aman, dan nyaman. Sehingga menyebabkan masyarakat dengan cepatnya beralih dari transportasi konvensional yang selama ini digunakan sebelum adanya transportasi online. Dengan munculnya aplikasi mobile. Selain menyediakan layanan transportasi, terdapat juga layanan pengiriman barang, pembelian makanan, atau barangbarang dari pasar swalayan dan bahkan dalam beberapa tahun kedepan perusahaan perusahaan tersebut akan berlomba lomba untuk sebisa mungkin melayani semua hal hal yang masyarakat butuhkan dalam kegiatan sehari hari.

Perusahaan didirikan pada tahun tahun 2012, ide ini tercetus dari perbincangan, dikabarkan ada sekelompok teman yang sedang menikmati teh bersama. Seperti warga Asia Tenggara pada umumnya, pembicaraan tersebut mengeluh tentang sulitnya mendapat taksi. Namun setelah itu, pendiri melakukan sesuatu yang tidak biasa memutuskan untuk menyelesaikan masalah ini. Dalam yang waktu singkat, tujuan sederhana bertransformasi menjadi sesuatu yang lebih besar membuat Asia Tenggara menjadi tempat yang lebih baik. 
Pada tahun 2014 perusahaan mulai didirikan untuk memperluas jangkauan nya di Asia Tenggara dengan meluncurkan layanan pertama berupa Taxi. Namun kemudahan, layanan memuaskan, aman serta nyaman harus juga ditunjang oleh kualitas yang baik dan tidak terlepas dari kinerja karyawan yang bekerja di perusahaan. Kinerja karyawan yang baik sangat dibutuhkan untuk membantu perusahaan bersaing dalam memenangkan pasar serta mempertahankan posisi perusahaan dalam persaingan. Kinerja merupakan suatu hasil kerja yang dihasilkan oleh seorang pekerja dalam mencapai tujuan atau target yang ditetapkan.

Customer Experience Department adalah salah satu proses bisnis yang dimiliki oleh perusahaan yang berfungsi sebagai front-end services dan bertanggung jawab langsung terhadap penanganan pelayanan kepada pengguna jasa. Oleh karena itu, sebuah pelayanan yang cepat dan akurat yang dapat diberikan kepada pengguna, merupakan salah satu kunci untuk meningkatkan customer satisfaction dalam memenangkan persaingan bisnis.

Salah satu strategi perusahaan untuk memenangkan pasar Indonesia adalah dengan memberikan layanan yang baik berupa produk dan jasa. Untuk memastikan dalam memberikan layanan yang baik, perusahaan sangat memperhatikan kinerja karyawan, salah satunya dengan melakukan penyesuaian objective key result pada setiap 3 bulan periode yang disesuaikan dengan keadaan pasar dan persaingan.

\section{TELAAH KEPUSTAKAAN \\ Gaya Kepemimpinan}

Menurut Terry (1985: 41) "Leadership is the relationship in which one person, or the leader, influence others to work together willingly on related task to attain that which the leader desires". Gaya kepemimpinan merupakan usaha dari pemimpin dalam mempengaruhi karyawan untuk mencapai tujuan perusahaan, sedangkan Menurut Dubrin (2005: 1143) "leadership is an attempt to influence a lot of people through communications in order to achieve its intended purpose, the way it affects a lot of people is done through instruction or orders." Sementara menurut Bass (1990: 1143). "Leadership style is model of the interaction between two or more in a group that resetting of the situation, perceptions and expectations of its members".

\section{Motivasi Karyawan}

Robbins dan Judge (2007: 1144): mendefinisikan "Motivation is process that explains the intensity, direction and persistence of an individual to achieve a goal". Sementara menurut Gibson (1996: 1144): "Motivation is the force that drives a person which raises and directs their behaviour". Lebih lanjut Luthans (1998: 34) menjelaskan motivasi sebagai: "in the current context, represents the process that arouses, energizes, directs and sustains behaviour and performance".

\section{Employee Engagement}

Menurut Perrin (2003: 90): "employee engagement is willingness and ability to help their company succeed, largely by providing discretionary effort on a sustainable basis." Menurut Robinson et al. (2004: 90) employee engagement adalah: "a positive attitude held by the employee towards the organization and its value." Employee engagement juga dipengaruhi oleh faktor yang melibatkan faktor emosional dan rasional serta berkaitan dengan overall work experience. Dan menurut Schaufeli dan Bakker (2010:22) employee engagement merupakan: "the psychological states the accompanies the behavioural investment of personal energy".

\section{Kinerja Karyawan}

Menurut Rivai (2004: 309). "Kinerja karyawan merupakan perilaku yang nyata yang ditampilkan setiap orang sebagai prestasi kerja yang dihasilkan oleh karyawan sesuai dengan perannya dalam perusahaan." Kinerja tidak hanya semata mata berdiri sendiri, tetapi bisa juga 
berhubungan dengan jobs satisfaction dan compensation, serta dipengaruhi oleh ability, desire dan environment. Sementara menurut Hasibuan (2006: 43) kinerja karyawan adalah: "suatu hasil kerja yang dicapai seseorang dalam melaksanakan tugas - tugas yang dibebankan kepadanya." Dan menurut Hyndman dan Anderson (1987: 1114) kinerja karyawan adalah: "is an achievement that can be accomplished from the behavior of members of the organization, through the stages of the input, process and output."

\section{Kaitan antar Variabel}

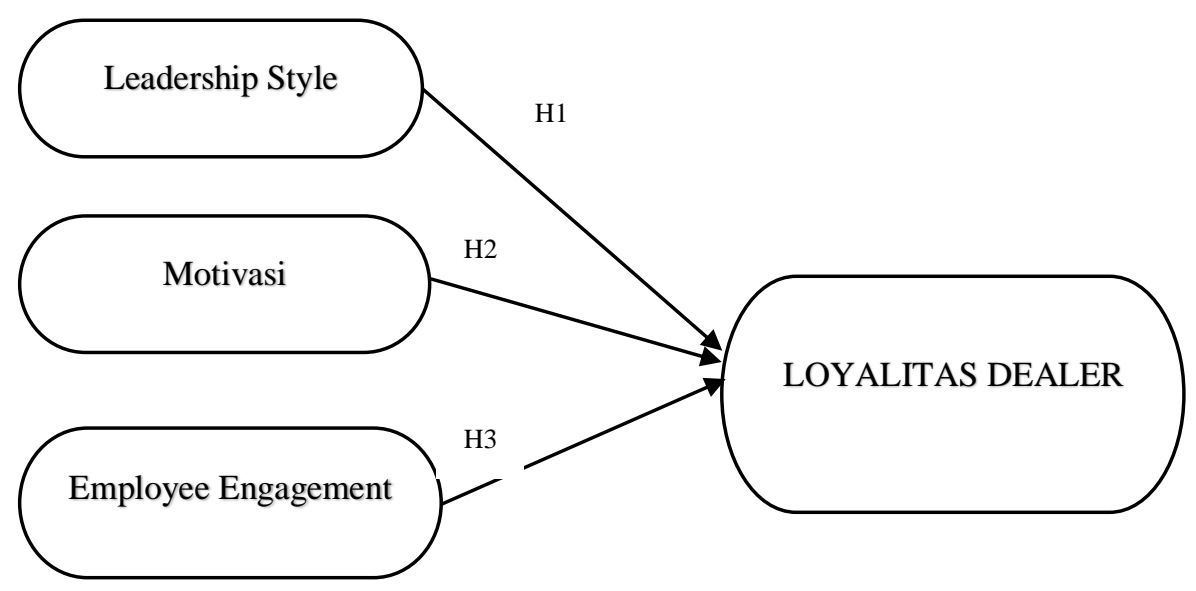

Gambar 2.1

Kerangka Pemikiran

Hipotesis dari model yang dibangun di atas adalah sebagai berikut:

$\mathrm{H}_{1}$ : Terdapat pengaruh gaya kepemimpinan terhadap kinerja karyawan.

$\mathrm{H}_{2}$ : Terdapat pengaruh motivasi terhadap kinerja karyawan.

$\mathrm{H}_{3}$ : Terdapat pengaruh employee engagement terhadap kinerja karyawan.

\section{METODOLOGI PENELITIAN}

Jenis Penelitian ini adalah penelitian deskriptif. Menurut Sekaran dan Bougie (2016: 43) "Descriptive studies are often designed to collect data that describe characteristics of objects (such as persons, organizations, products, or brands), events, or situations" yaitu penelitian dengan tujuan untuk menguraikan sifat-sifat (karakteristik) suatu keadaan, sehingga dengan menggunakan metode ini dapat diketahui keterkaitan antara gaya kepemimpinan, motivasi, dan employee engagement terhadap kinerja karyawan pada Customer Experience Deparment. Penelitian ini menggunakan metode deskriptif cross sectional.

Peneliti menggunakan teknik convenience sampling dalam pengambilan sampel. Sekaran dan Bougie (2016:247) menyatakan bahwa "convenience sampling refers to the collection of information from members of the population who are conveniently available to provide it". Faktor efisiensi waktu, serta sampel populasi yang dibutuhkan untuk data penelitian ini cukup terjangkau disekitar area kerja peneliti merupakan alasan peneliti untuk memilih metode convinince sampling. Jumlah populasi Customer Experience Department diperusahaan berjumlah kurang lebih 600 orang, sehingga penelitian ini menggunakan sampel sebesar 108 responden, jumlah ini mengacu pada pendapat Hair, Jr. et al. (1995) jika subjeknya homogen dan variabelnya tidak terlalu banyak. mengemukakan bahwa umumnya peneliti tidak akan menggunakan sampel yang lebih kecil dari 50, dan lebih disukai 100 atau lebih

Jenis data yang dapat digunakan dalam penelitian ini adalah data primer. Data primer adalah seluruh data yang telah dikumpulkan sendiri oleh peneliti agar dapat menjawab suatu permasalahan penelitiannya. 
Skala Likert dinyatakan sebagai skala nominal karena alternatif tanggapannya bersifat kategorik yang dinyatakan dalam lima kategori, yaitu (1) sangat tidak setuju, (2) tidak setuju, (3) netral, (4) setuju dan (5) sangat setuju.

\section{HASIL DAN PEMBAHASAN}

Untuk pengujian validitas dalam penelitian tiap butir menggunakan analisis faktor, yaitu mengkorelasikan antar skor item instrumen dalam suatu faktor, dan mengkorelasikan skor faktor dengan skor total yang merupakan jumlah tiap skor Sanusi (2011),. Sekurang-kurangnya terdapat dua kriteria untuk menilai validitas suatu item. Pertama, apabila korelasi setiap faktor tersebut positif dan besarnya 0,3 ke atas, maka faktor tersebut merupakan konstruk yang kuat, yang berarti valid. Kedua, item pertanyaan dianggap valid jika nilai validitasnya lebih besar daripada nilai korelasi product moment ( $\mathrm{r}$ tabel) pada tingkat signifikasi 0,05.

Pengujian Reliabilitas pada penelitian ini dilakukan hanya pada satu waktu, kemudian dilakukan perbandingan dengan pertanyaan yang lain atau dengan pengukuran korelasi antar jawaban. Pada program SPSS, metode ini dilakukan dengan metode Cronbach Alpha, di mana suatu kuesioner dikatakan reliabel jika nilai Cronbach Alpha lebih besar dari 0,60. Dari hasil olah data uji statistik reliabilitas memperlihatkan bahwa nilai cronbach's alpha berada diatas batas minimal 0,60, demikian seluruh variabel reliable, sehingga dapat disimpulkan bahwa skala pengukuran Gaya Kepemimpinan, Motivasi Karyawan, Employee Engagement dan Kinerja Karyawan mempunyai reliabilitas yang baik.

Tabel 3.1

Hasil pengujian Reliabilitas

\begin{tabular}{|l|c|}
\hline \multicolumn{1}{|c|}{ Item } & Cronbach Alpha \\
\hline Gaya Kepemimpinan (X1) & 0.614 \\
\hline Motivasi Karyawan (X2) & 0.615 \\
\hline Employee Engagement (X3) & 0.792 \\
\hline Kinerja Karyawan (Y) & 0.847 \\
\hline
\end{tabular}

$\mathrm{R}$ square atau koefisen determinan pada penelitian ini sebesar 0,183 atau 18,3\%, menunjukkan bahwa Kinerja Karyawan dipengaruhi ketiga variabel independen yang dipakai dalam penelitian ini (yakni independen Gaya Kepemimpinan $\left(\mathrm{X}_{1}\right)$, Motivasi Karyawan $\left(\mathrm{X}_{2}\right)$ dan Employee Engagement $\left(\mathrm{X}_{3}\right)$ ) sebesar 18,3\%, dan masih ada pengaruh dari faktor lainnya yaitu $81.7 \%$ dari faktor lainnya.

Tabel 3.2

Hasil Rekapitulasi Pengujian Hipotesis

\begin{tabular}{|l|l|c|}
\hline Hipotesis & \multicolumn{1}{|c|}{ Pengujian Hipotesis } & Hasil \\
\hline $\mathrm{H}_{1}$ & $\begin{array}{l}\text { Terdapat pengaruh positif gaya kepemimpinan } \\
\text { terhadap kinerja karyawan }\end{array}$ & Tidak ditolak \\
\hline $\mathrm{H}_{2}$ & $\begin{array}{l}\text { Terdapat pengaruh positif motivasi karyawan } \\
\text { terhadap kinerja karyawan }\end{array}$ & Tidak ditolak \\
\hline $\mathrm{H}_{3}$ & $\begin{array}{l}\text { Terdapat pengaruh positif employee } \\
\text { engagement terhadap kinerja karyawan }\end{array}$ & Tidak ditolak \\
\hline
\end{tabular}

Berdasarkan hasil pengolahan, dapat diketahui bahwa gaya kepemimpinan berpengaruh positif terhadap kinerja karyawan, di mana gaya kepemimpinan memperoleh nilai koefisien regresinya sebesar 0.402 , sedangkan motivasi karyawan meperoleh nilai koefisien regresi sebesar 0.250, dan employee engagement memperoleh nilai 0.108 
Berdasarkan data di atas, dapat disimpulkan bahwa Gaya Kepemimpinan, mempunyai pengaruh yang paling besar diantara variabel penelitian yang lain, dilanjutkan dengan variabel Motivasi Karyawan.

\section{KESIMPULAN DAN SARAN}

Pada penelitian ini penulis menemukan bahwa terdapat hubungan positif dan signifikan antara gaya kepemimpinan dan kinerja karyawan dengan $\beta_{1}=0,402$, artinya apabila variabel Gaya Kepemimpinan $\left(\mathrm{X}_{1}\right)$ meningkat dan variabel Motivasi Karyawan $\left(\mathrm{X}_{2}\right)$ dan Employee Engagement $\left(\mathrm{X}_{3}\right)$ tetap maka variabel Kinerja Karyawan $(\mathrm{Y})$ akan meningkat sebesar 0,402. Sesuai dengan penelitian Suharno et al. (2017) yang berjudul "Factors affecting employee performance of PT. Kiyokuni Indonesia". Terdapat hubungan positif dan signifikan antara gaya kepemimpinan, motivasi karyawan dan disiplin terhadap kinerja karyawan.

Selanjutnya pada saat dilakukan pengujian pada terhadap variabel motivasi karyawan terhadap kinerja karyawan, menghasilkan $\beta 2=0,250$, artinya apabila variabel variabel Motivasi Karyawan (X2) meningkat dan variabel Gaya Kepemimpinan (X1) dan Employee Engagement (X3) tetap maka variabel Kinerja Karyawan (Y) akan meningkat sebesar 0,250. Maka penelitian ini mendukung penelitian yang dilakukan oleh Riyadi (2012) yang berjudul "Pengaruh Kompensasi Finansial, Gaya Kepemimpinan, dan Motivasi Kerja Terhadap Kinerja Karyawan pada Perusahaan Manufaktur di Jawa Timur". Yang menyatakan kompensasi finansial tidak mempengaruhi kinerja karyawan, gaya kepemimpinan secara signifikan mempengaruhi kinerja karyawan, dan motivasi kerja secara signifikan mempengaruhi kinerja karyawan

Pengujian yang terakhir adalah pengujian variabel employee engagement dengan hasil $\beta_{3}=0,108$, artinya apabila variabel variabel Employee Engagement $\left(\mathrm{X}_{3}\right)$ meningkat dan variabel Gaya Kepemimpinan $\left(\mathrm{X}_{1}\right)$ dan Motivasi Karyawan $\left(\mathrm{X}_{2}\right)$ tetap maka variabel Kinerja Karyawan (Y) akan meningkat sebesar 0,108. Hasil tersebut mendukung penelirian yang dilakukan oleh Markos dan Sridevi. (2010) yang berjudul "Employee Engagement: The Key to Improving performance". Yang menyebtukan terdapat hubungan positif antara employee engagement terhadap kinerja karyawan.

Tabel 4.1

Hasil Uji Regresi Linier Berganda

\begin{tabular}{|l|c|c|c|c|c|}
\hline \multirow{2}{*}{ Model } & \multicolumn{2}{|c|}{$\begin{array}{c}\text { Unstandardized } \\
\text { Coefficients }\end{array}$} & $\begin{array}{c}\text { Standardized } \\
\text { Coefficients }\end{array}$ & \multirow{2}{*}{$\mathrm{t}$} & \multirow{2}{*}{ Sig. } \\
\cline { 2 - 5 } & $\mathrm{B}$ & Std. Error & beta & & \\
\hline$($ Constant $)$ & 6,133 & 2.569 & & 2.387 & 0,019 \\
\hline $\begin{array}{l}\text { Gaya } \\
\text { Kepemimpinan }\end{array}$ & 0,402 & 0,122 & 0,298 & 3,287 & 0,001 \\
\hline $\begin{array}{l}\text { Motivasi } \\
\text { Karyawan }\end{array}$ & 0,250 & 0,109 & 0,210 & 2,306 & 0,023 \\
\hline $\begin{array}{l}\text { Employee } \\
\text { Engagement }\end{array}$ & 0,108 & 0,046 & 0,207 & 2,351 & 0,021 \\
\hline
\end{tabular}

\section{Penutup}

Penelitian ini bertujuan untuk mengetahui pengaruh gaya kepemimpinan, motivasi karyawan, employee engagement terhadap kinerja karyawan pada Customer Experience Department. Berdasarkan hasil analisis dapat disimpulkan bahwa:

1. Gaya kepemimpinan berpengaruh positif terhadap kinerja karyawan. Sesuai penelitian Suharno et al. (2017), Gaya kepemimpinan yang baik dapat kinerja karyawan secara 
positif. Karyawan akan memberikan hasil yang baik jika pemimpin dapat mendelegasikan tugas dalam gaya kepemimpinannya.

2. Motivasi berpengaruh positif terhadap kinerja karyawan. Hasil tersebut sesuai dengan penelitian Riyadi (2012) yang melakukan penelitian terhadap pengaruh kompensasi finansial, gaya kepemimpinan, dan motivasi kerja terhadap kinerja karyawan di perusahaan maunfaktur di Jawa.

3. Employee engagament berpengaruh positif terhadap kinerja karyawan. Penelitian ini sesuai dengan hasil penelitian Prawiro, Markos dan Sridevi. (2010) yang membuahkan hasil bahwa kinerja karyawan dipengaruhi oleh employee engagement.

\section{Daftar Rujukan/Pustaka}

Dubrin, Andrew J. (2005). Leadership (Terjemahan). Edisi Kedua. Prenada Media. Jakarta.

Bass, B. M. (1990). Bass and StogdillÕ̂s handbook of leadership: Theory, research and management applications (3rd ed.). New York: Free Press.

Robbins, S.P. \& Judge. (2007). Perilaku Organisasi. Salemba Empat, Jakarta.

Gibson, Ivancevich, Donnely. (1997). Organizations (Terjemahan), Cetakan Keempat, Jakarta: PT. Gelora Aksara Pratama.

Luthans, F. (1998), Organizational Behavior, Irwin McGraw-Hill, Mass.

Perrin T. (2003). Working Today: Understanding What Drives Employee Engagement The 2003 Towers Perrin Talent Report U.S Report. [Online] Available: http://www.towersperrin.com/tp/getwebcachedoc? Webc = HRS /USA/2003/200309/Talent_2003.pdf (October 30, 2008)

Robinson D., Perryman S., and Hayday S. (2004). The Drivers of Employee Engagement Report 408, Institute for Employment Studies, UK

Schaufeli, W.B. and Bakker, A.B. (2010), "Defining and measuring work engagement: bringing clarity to the concept", in Bakker, A.B. and Leiter, M.P. (Eds), Work Engagement: A Handbook of Essential Theory and Research, Psychology Press, Hove, NY, pp. 10-24.

Rivai, V. (2011), Manajemen Sumber Daya Manusia untuk Perusahaan Dari Teori ke Praktek, Grafindo Persada, Jakarta.

Hasibuan. (2007). Manajemen Sumber Daya Manusia, cetakan kesembilan, Jakarta : PT Bumi Aksara.

Sekaran, Uma dan Bougie, Roger (2016). Research Methods for Business. United Kingdom : Jhon Wiley \& Sons Ltd.

Hair, J.F., Anderson, R.E., Tatham, R.L. and Black, W.C. (2003), Multivariate Analysis, Pearson Education Inc, Delhi.

Sugiyono. (2012). Metode Penelitian Kuantitatif, Kualitatif dan R\&D. Bandung: Alfabeta.

Pawirosumarto, Suharno, Purwanto Katijan Sarjana, and Muzaffar Muchtar. 2017. "Factors Affecting Employee Performance of PT. Kiyokuni Indonesia." International Journal of Law and Management 59(4):IJLMA-03-2016-0031. Retrieved (http://www.emeraldinsight.com/doi/10.1108/IJLMA-03-2016-0031).

Riyadi, Slamet. (2011). "Pengaruh Kompensasi Finansial, Gaya Kepemimpinan, Dan Motivasi Kerja Terhadap Kinerja Karyawan Pada Perusahaan Manufaktur Di Jawa Timur.” Jurnal Manajemen Dan Kewirausahaan.

Sanusi, Anwar. 2011. Metodologi Penelitian Bisnis. Jakarta: Penerbit Salemba Empat

Markos, Solomon and Sandhya Sridevi. 2010. "Employee Engagement : The Key to Improving Performance." International Journal of Business and Management 5(12):89-96.

Davis, Keith \& John W. Newstroom. 1985. Perilaku Dalam Organisasi, Alih Bahasa: Agus Dharma, Jakarta: Erlangga. 